\title{
PENGARUH PELATIHAN RELAKSASI ZIKIR TERHADAP PENINGKATAN KESEJAHTERAAN SUBJEKTIF ISTRI YANG MENGALAMI INFERTILITAS
}

\section{THE EFFECT OF ZIKR RELAXATION TRAINING TO INCREASE SUBJECTIVE WELL BEING OF WIFE INFERTILITY}

\author{
Dina Wahyunita \\ Fakultas Psikologi dan Ilmu Sosial Budaya Universitas Islam Indonesia Yogyakarta \\ Email:dinawahyunita@yahoo.com. \\ Tina Afiatin \\ Fakultas Psikologi Universitas Gadjah Mada Yogyakarta \\ RA. Retno Kumolohadi \\ Fakultas Psikologi dan Ilmu Sosial Budaya Universitas Islam Indonesia Yogyakarta
}

\begin{abstract}
This research aims at identifying the effect of zikr relaxation training to increase subjective well being of wife's infertility. Zikr relaxation training is a training which using zikr relaxation concept from Maimunah (2011) involving education of infertility, education of zikr relaxation, practice zikr relaxation, experience discussion, and self monitoring. The subject of research was four wife infertility primary. The data collected was conducted using subjective well being scale, interview, and observation. The research design used was one group pretest posttest design. Quantitative and qualitative analysis were used to analyze data. The result showed that all aspects of subjective well being difference significantly infertility before getting zikr relaxation training and after getting training with value $Z=-1,826, p=0,034(p<0,05), r=-0,913$. Effect size of indicaties that zikr relaxation training has a large effect to aspect of life satisfaction, positive affect, and negative affect because able to explain variant of life satisfaction, variant of positive affect, and variant of negative affect equal to $83,36 \%$. The conclusion of this Research is subjective well being of wife infertility increase after following zikr relaxation training. Zikr Relaxation training could increase aspect of life satisfaction and affective aspect of wife infertility.

Key words: Subjective Well Being, Zikr Relaxation, Wife Infertility.
\end{abstract}

\begin{abstract}
ABSTRAK
Penelitian ini bertujuan untuk mengetahui pengaruh pelatihan relaksasi zikir terhadap peningkatan kesejahteraan subjektif istri yang mengalami infertilitas. Pelatihan relaksasi zikir adalah pelatihan yang menggunakan konsep relaksasi zikir dari Maimunah (2011) yang terdiri atas materi infertilitas, materi relaksasi zikir, praktek relaksasi zikir, diskusi pengalaman, dan self monitoring. Subjek dalam penelitian ini adalah empat orang istri yang mengalami infertilitas primer. Pengumpulan data dilakukan dengan menggunakan skala kesejahteraan subjektif, wawancara, dan observasi. Desain penelitian yang digunakan adalah one group pretest posttest design. Analisis penelitian yang digunakan adalah analisis kuantitatif dan kualitatif. Hasil penelitian, yaitu semua aspek pada kesejahteraan subjektif menunjukkan adanya perbedaan yang signifikan pada istri yang mengalami infertilitas sebelum mendapatkan pelatihan relaksasi zikir dengan setelah mendapatkan pelatihan dengan nilai $Z=-1,826, p=0,034(p<0,05), r=-0,913$. Hasil estimasi effect size mengindikasikan bahwa pelatihan relaksasi zikir memiliki a large effect terhadap aspek kepuasan hidup, afek positif, dan afek negatif karena mampu menjelaskan varian kepuasan hidup, varian afek positif, dan varian afek negatif sebesar $83,36 \%$. Kesimpulan penelitian ini adalah kesejahteraan subjektif istri yang
\end{abstract}


mengalami infertilitas lebih tinggi setelah mengikuti pelatihan relaksasi zikir dibandingkan sebelum mengikuti pelatihan. Kesejahteraan subjektif istri infertilitas meningkat setelah mengikuti pelatihan relaksasi zikir. Pelatihan relaksasi zikir dapat meningkatkan aspek kepuasan hidup dan aspek afektif pada istri yang mengalami infertilitas.

Kata Kunci : Kesejahteraan Subjektif, Relaksasi zikir, Istri Infertilitas

Hipertensi merupakan salah satu penyakit kronis (Sustrani, Alam, \& Hadibroto, 2006). Penyakit kronis adalah penyakit degeneratif yang berkembang dan berkelanjutan dalam kurun waktu yang lama. Seseorang yang telah didiagnosis mengidap penyakit kronis pasti akan merasakan kecemasan. Rasa cemas itu berasal dari rasa takut akan kelanjutan dari penyakitnya itu, takut ditinggalkan dan dijauhi oleh keluarga dan temantemannya, rasa tidak berdaya, dan yang paling membuat cemas adalah kematian. Hal ini dikarenakan penyakit kronis itu sulit disembuhkan dan dihilangkan dari tubuh pasien. Dokter hanya bisa memberikan terapi untuk mengurangi rasa sakit dan gejala-gejalanya (Rachmawati, 2007).

Berdasarkan hasil asesmen yang dilakukan di Puskesmas Godean II Sleman Daerah Istimewa Yogyakarta diketahui bahwa jumlah pasien hipertensi di wilayah kerja puskesmas ini cukup banyak. Data terakhir yang dimiliki oleh perawat Puskesmas, pada tahun 2011 terdapat sebanyak 1.475 kasus pasien hipertensi. Sedangkan pada tahun 2012 terdapat sebanyak 1.303 kasus hipertensi. Menurut perawat puskesmas, jumlah pasien hipertensi memang cukup banyak.

Kecemasan merupakan salah satu kondisi psikologis yang biasa terjadi karena pengalaman tidak menyenangkan yang dialami oleh setiap manusia. Menurut Nevid, Rathus, dan Greene (2005), kece- masan merupakan suatu keadaan khawatir, gugup, atau takut ketika berhadapan dengan pengalaman yang sulit dalam kehidupan seseorang dan menganggap bahwa sesuatu yang buruk terjadi. Kecemasan dapat menjadi abnormal atau tidak wajar ketika tingkatannya tidak sesuai dengan proporsi ancaman atau bila sepertinya datang tanpa ada penyebabnya yang bisa mengganggu aktivitas sehari-hari (Nevid dkk, 2005). Kecemasan juga disebut abnormal ketika kadar kecemasannya berlebih di mana pasien merasa tidak berdaya ataupun kesulitan untuk mengatasinya (Kaplan \& Saddock, 1994).

Berdasarkan hasil wawancara tersebut, para pasien hipertensi mengalami ciri-ciri kecemasan dari penyakit yang mereka alami. Pasien hipertensi lebih merasakan kecemasan baik secara fisik maupun secara psikologis. Kondisi seperti ini bisa memengaruhi kondisi pikiran, perasaan, dan fisik pasien hipertensi. Kecemasan merupakan perasaan yang tidak menyenangkan sebagai manifestasi dari berbagai perasaan emosi yang terjadi pada saat individu sedang mengalami tekanan perasaan (frustrasi) dan pertentangan batin (konflik).

Menurut Santrock (2002), status kesehatan seseorang menjadi persoalan utama pada masa dewasa tengah (pralansia). Pada masa ini, pralansia lebih banyak menghabiskan waktu untuk mengkhawatirkan tentang kesehatan. Wilianto (2009) 
mengemukakan dalam penelitiannya bahwa kecemasan bisa meningkatkan tekanan darah, dan berbahaya jika terjadi pada orang-orang yang menderita hipertensi. Penurunan kecemasan menjadi salah satu hal yang penting untuk dilakukan agar tekanan darah dan denyut jantung penderita tidak meningkat.

Pada penelitian ini terapi relaksasi yang digunakan adalah relaksasi otot progresif. Relaksasi otot adalah salah satu teknik dalam terapi perilaku yang dikembangkan oleh Jacobson dan Wolpe untuk mengurangi ketegangan dan kecemasan (Goldfried \& Davidson, 1976). Kemudian akan dimodifikasi dengan psikoterapi Islam, yaitu dengan metode zikir. Zikir merupakan suatu cara atau media untuk menyebut dan mengingat nama Allah, oleh karenanya bentuk aktivitas yang tujuannya mendekatkan diri kepada Allah dinamakan zikir seperti shalat dan puasa.

Peristiwa yang dialami oleh pasien hipertensi karena kurang adanya penerimaan diri mereka sendiri sebagai pasien hipertensi sehingga kecemasan itu muncul dari dalam diri pasien yang menyebabkan tekanan darahnya menjadi naik. Usia madya merupakan masa di mana pria dan wanita meninggalkan ciri-ciri jasmani dan perilaku masa dewasanya dan memasuki suatu periode dalam kehidupan yang akan diliputi oleh ciri-ciri jasmani dan perilaku baru. Penyesuaian yang radikal terhadap peran, pola hidup dan berbagai perubahan fisik, akan cenderung merusak homeostasis fisik dan psikologis seseorang dan kemudian membawanya ke masa stres.
Terapi relaksasi zikir diharapkan dapat meminimalisir kecemasan pada pasien hipertensi itu sendiri. Proses relaksasi zikir sangat erat kaitannya dengan sebuah kondisi dimana seseorang harus mampu terlebih dahulu menerima berbagai kenyataan yang tidak menyenangkan dengan tenang dan terkendali, kondisi ini disebut dengan kelapangdadaan (Nashori, 2007). Ketika berlapangdada, seseorang menerima segala peristiwa dari Allah Swt, maka ia memiliki kekuatan dalam dirinya untuk bertahan dan tidak berputus asa ketika dihadapkan pada situasi yang tidak menyenangkan secara fisik maupun psikologis. Dalam alQuran dan Hadis dan para pemikir Islam memberikan tuntutan bagaimana agar dalam meng-arungi kehidupan ini bebas dari rasa cemas, tegang, konflik, stress maupun depresi, di antaranya dengan memper-banyak zikir dan doa kepada Allah sebagai Yang Maha Penyembuh (Nashori, 2007).

Relaksasi otot progresif terdiri atas beberapa tahap, yaitu tahap pertama, relaksasi lengan. Tahap kedua, relaksasi daerah muka, leher, pundak dan punggung atas. Tahap ketiga, relaksasi dada perut dan pinggang. Tahap keempat, relaksasi pinggang, paha, dan betis diikuti oleh relaksasi seluruh tubuh. Manfaat relaksasi otot progresif terhadap kecemasan pada pralansia adalah dapat mengurangi hipertensi, sakit kepala, dan insomnia tingkat kecemasan, dapat meningkatkan harga diri dan keyakinan diri seseorang dan meningkatkan hubungan interpersonal. Dengan melakukan relaksasi otot tersebut, pralansia yang mengalami 
kecemasan dan memiliki tekanan darah tinggi dapat menurunkan tekanan darah, rasa marah, cemas, takut, khawatir, dan lain-lain.

Suatu penelitian yang dilakukan oleh Newberg (2000) menyimpulkan bahwa terdapat hubungan yang positif antara pengalaman spiritual dan kesehatan. Salah satu contoh misalnya mereka yang rajin dan secara teratur menjalani meditasi dan berdoa serta berzikir memiliki taraf kesehatan fisik dan mental yang lebih tinggi daripada mereka yang tidak mengamalkan meditasi serta berdoa dan berzikir. Dikemukakan bahwa pengalaman meditasi serta berdoa dan berzikir itu dapat menurunkan tekanan darah dan denyut jantung, oleh karenanya resiko penyakit jantung dan stroke dapat dihindari.

Berdasarkan penjelasan di atas, dirumuskan sebuah hipotesis penelitian. Hipotesis penelitian ini adalah ada perbedaan tingkat kecemasan pasien hipertensi esensial pralansia yang mendapatkan terapi relaksasi zikir dengan tingkat kecemasan pasien hipertensi esensial pralansia yang tidak mendapatkan terapi relaksasi zikir.

\section{METODE PENELITIAN}

\section{Rancangan Eskperimen}

Penelitian ini merupakan penelitian kuasi-eksperimen dengan model rancangan penelitian yang akan digunakan adalah pretest-posttest control group design (Shadish, Cook, \& Campbell, 2002). Desain ini bertujuan untuk melihat efek suatu perlakuan terhadap kelompok yang diberi perlakuan dan kelompok kontrol. Pemilihan subjek ditetapkan dengan cara tidak random yaitu dengan cara matching.

\section{Subjek Penelitian}

Subjek penelitian ini adalah sebagai berikut (a) pasien hipertensi esensial pralansia berusia 45-59 tahun, (b) beragama islam, (c) memiliki skor kecemasan dari kategori sedang sampai tinggi, dan (d) berada pada kategori hipertensi esensial stadium 1 dan 2 .

\section{Metode Pengumpulan Data}

Pengumpulan data dalam penelitian ini diperoleh melalui wawancara awal dan observasi. Selain itu penelitian ini juga menggunakan pengukuran dengan skala kecemasan yang disusun oleh Dony (2012) yang terdiri atas 20 aitem setelah tryout. Penyusunan skala kecemasan ini memuat aspek emosi, kognitif, fisik, dan perilaku (Calhoun \& Acocella, 1990; Greenberger \& Padesky, 1995; Nevid, $d k k, 2005)$. Skala tersebut menggunakan empat alternatif pilihan respon yaitu HTP (Hampir Tidak Pernah), J (Jarang), S (Sering), dan HS (Hampir Selalu). Jumlah aitem pada skala kecemasan adalah 20 butir. Rentang skor yang diberikan untuk masing-masing jawaban bergerak dari 1-4. Skor 1 yaitu untuk pilihan jawaban TP, 2 untuk pilihan jawaban J, 3 untuk jawaban S, dan 4 untuk jawaban HS. Skor terendah yang mungkin didapat subjek adalah 20 dan tertinggi adalah 80 . Semakin tinggi skor yang didapat maka semakin tinggi tingkat kecemasannya, sedangkan semakin rendah skor yang didapat subjek maka semakin rendah 
tingkat kecemasannya. Selanjutnya peneliti melakukan kategorisasi skor menjadi tiga yaitu rendah, sedang, tinggi (Azwar, 2000).

\section{Prosedur Penelitian}

Peneliti memilih terapi relaksasi zikir untuk menurunkan kecemasan pada pasien hipertensi esensial pralansia. Adapun tahapan terapi relaksasi zikir dalam penelitian ini terdiri atas sesi psikoedukasi dengan model psikologi dan pendekatan agama Islam, sesi harapanku, sesi relaksasi otot progresif, sesi psikoedukasi mengenai zikir, sesi latihan zikir, sesi sharing atau presentasi diri, dan sesi homework atau tugas rumah. Dari tahapan terapi tersebut diharapkan dapat mengatasi masalah yang dialami oleh subjek.

\section{Metode Analisis Data}

Metode analisis data menggunakan analisis kuantitatif dan kualitatif. Analisis data kuantitatif menggunakan paket Statistical Product and Service Solution (SPSS) for windows. Pengujian hipotesis dalam penelitian ini dengan dilakukan dengan analisis nonparametrik $U$ Mann Whitney Test. Hal ini dikarenakan jumlah sampelnya kecil. Selain itu untuk mengetahui signifikansi perbedaan antara kelompok eksperimen dan kelompok kontrol setelah diberikan terapi kelompok. Analisis data kualitatif dilakukan untuk mengetahui proses yang terjadi pada masing-masing subjek. Analisis kuantitatif akan digunakan untuk menjabarkan data kualitatif yang diperoleh selama intervensi berlangsung.

\section{HASIL PENELITIAN}

\section{Deskripsi Data Penelitian}

Tabel 1. Deskripsi data subjek penelitian kelompok eksperimen

\begin{tabular}{ccccccccc}
\hline Subjek & $\begin{array}{l}\text { Jenis } \\
\text { Kelamin }\end{array}$ & Usia & \multicolumn{7}{c}{ Pengukuran } \\
& & & Prates & Pascates & $\begin{array}{c}\text { Tindak } \\
\text { lanjut }\end{array}$ & $\begin{array}{c}\text { Gained } \\
\text { score(pra- } \\
\text { pasca) }\end{array}$ & $\begin{array}{c}\text { Gained } \\
\text { score(pasca- } \\
\text { tindaklanjut) }\end{array}$ & $\begin{array}{c}\text { Gained } \\
\text { score(pra- } \\
\text { indaklanjut) }\end{array}$ \\
\hline SJ & P & 45th & 52 & 49 & 33 & 3 & 16 & 19 \\
SP & P & 45th & 44 & 35 & 32 & 9 & 3 & 12 \\
SW & P & 52th & 47 & 49 & 33 & -2 & 16 & 14 \\
HP & P & 52th & 46 & 38 & 34 & 8 & 4 & 12 \\
TW & P & 52th & 50 & 48 & 35 & 2 & 13 & 15 \\
\hline
\end{tabular}


Tabel 2. Deskripsi data subjek penelitian kelompok kontrol

\begin{tabular}{|c|c|c|c|c|c|c|c|c|}
\hline \multirow[t]{2}{*}{ Subjek } & \multirow{2}{*}{$\begin{array}{l}\text { Jenis } \\
\text { Kelamin }\end{array}$} & \multirow[t]{2}{*}{ Usia } & \multicolumn{5}{|c|}{ Pengukuran } & \multirow[b]{2}{*}{$\begin{array}{c}\text { Gained } \\
\text { score(pra- } \\
\text { indaklanjut) }\end{array}$} \\
\hline & & & Prates & Pascates & $\begin{array}{r}\text { Tindak } \\
\text { lanjut }\end{array}$ & $\begin{array}{c}\text { Gained } \\
\text { score(pra- } \\
\text { pasca) }\end{array}$ & $\begin{array}{c}\text { Gained } \\
\text { score(pasca- } \\
\text { tindaklanjut) }\end{array}$ & \\
\hline RB & $P$ & 50th & 56 & 60 & 60 & -4 & 0 & -4 \\
\hline MJ & $\mathrm{P}$ & 50th & 46 & 55 & 56 & -9 & -1 & -10 \\
\hline SM & $P$ & 53th & 43 & 53 & 54 & -10 & -1 & -11 \\
\hline SG & $P$ & 50th & 54 & 48 & 50 & 6 & -2 & 4 \\
\hline ST & $P$ & 52th & 64 & 54 & 54 & 10 & 0 & 10 \\
\hline
\end{tabular}

Tabel 3. Deskripsi data prates, pascates, dan tindak lanjut

\begin{tabular}{ccccccccc}
\hline Klasifikasi & \multicolumn{3}{c}{ Kelompok Eksperimen } & \multicolumn{4}{c}{ Kelompok Kontrol } \\
& Min & Max & Mean & SD & Min & Max & Mean & SD \\
\hline Prates & 44 & 52 & 47,80 & 3,194 & 43 & 64 & 52,60 & 8,355 \\
Pascates & 35 & 49 & 43,80 & 6,760 & 48 & 60 & 54,00 & 4,301 \\
Tindak Lanjut & 32 & 35 & 33,40 & 1,140 & 50 & 60 & 54,80 & 3,633 \\
\hline
\end{tabular}

\section{Hasil Uji Hipotesis}

Hipotesis dalam penelitian ini adalah ada perbedaan tingkat kecemasan antara kelompok eksperimen yang diberikan terapi relaksasi zikir dan kelompok kontrol yang tidak mendapatkan terapi relaksasi zikir. Pengujian hipotesis dilakukan dengan uji statistic yaitu $U$ Mann Whitney. Hasil analisis data dengan uj $U$ Mann Whitney terdapat pada tabel di bawah ini :

Tabel 4. Rangkuman uji hipotesis

\begin{tabular}{|l|r|r|r|}
\hline & \multicolumn{1}{|c|}{ Prates } & \multicolumn{1}{c|}{ Pascates } & \multicolumn{1}{c|}{ Followup } \\
\hline Mann-Whitney U & 8.500 & 2.500 & .000 \\
Wilcoxon W & 23.500 & 17.500 & 15.000 \\
Z & -.838 & -2.102 & -2.627 \\
Asymp. Sig. (2-tailed) & .402 & .036 & .009 \\
Exact Sig. [2*(1-tailed & $.421^{\mathrm{a}}$ & $.032^{\mathrm{a}}$ & $.008^{\mathrm{a}}$ \\
Sig.)] & & & \\
\hline
\end{tabular}

Tabel 4 menunjukkan ada perbedaan tingkat kecemasan yang signifikan antara kelompok eksperimen dan kelompok kontrol pada saat tindak lanjut, yang ditunjukkan dengan skor $Z=-2,627$ dan $p=0,008(p<0,05)$. Hal ini menunjukkan bahwa kelompok eskperimen mengalami penurunan kecemasan setelah diberi- 
kan terapi relaksasi zikir daripada kelompok kontrol yang tidak diberi terapi relaksasi zikir. Berdasarkan hasil analisis hipotesis dapat diterima.

\section{PEMBAHASAN}

Penelitian ini bertujuan untuk mengetahui pengaruh terapi relaksasi zikir untuk menurunkan kecemasan pada pasien hipertensi esensial pralansia pada kelompok eksperimen dan kelompok kontrol. Selain itu juga untuk mengetahui perbedaan tingkat kecemasan sebelum dan sesudah diberikan terapi relaksasi zikir pada kelompok eksperimen dan kelompok kontrol.

Berdasarkan analisis data yang telah dilakukan didapatkan hasil bahwa terdapat perbedaan tingkat kecemasan antara kelompok eksperimen dan kontrol setelah diberi terapi relaksasi zikir. Hasil analisis $U$ Mann Whitney menunjukkan skor $Z=$ $-2,627$ dan nilai $p=0,008(p<0,05)$. Hal ini menunjukkan bahwa ada perbedaan tingkat kecemasan pasien hipertensi esensial pralansia yang signifikan antara kelompok eksperimen dan kelompok kontrol setelah diberi terapi relaksasi zikir. Kelompok eksperimen menunjukkan tingkat kecemasan lebih rendah dibandingkan dengan kelompok kontrol. Hal ini menandakan bahwa terapi relaksasi zikir mempunyai pengaruh terhadap penurunan kecemasan pada pasien hipertensi esensial pralansia setelah diberi terapi relaksasi zikir. Setelah dua minggu dilakukan tindak lanjut untuk melihat pengaruh terapi relaksasi zikir terhadap penurunan kecemasan pasien hipertensi esensial pralansia. Berdasarkan analisis $U$ Mann Whitney menunjukkan skor $\mathrm{Z}=$ 2,627 dan nilai $p=0,008(p<0,05)$. Hal ini menunjukkan bahwa ada perbedaan tingkat kecemasan antara kelompok eksperimen dan kelompok kontrol setelah diberi terapi dan pada saat tindak lanjut.

Hasil penelitian ini mendukung penelitian terdahulu yang telah dilakukan oleh Maimunah (2011) yang menggunakan relaksasi dengan zikir untuk mengatasi kecemasan. Dalam penelitian tersebut terbukti signifikan bahwa relaksasi dengan zikir dapat menurunkan tingkat kecemasan yang dialami subjek. Hal ini juga sesuai dengan penelitian yang telah dilakukan oleh Hoelscher dan Lichstein (1986) menunjukkan bahwa relaksasi dapat menurunkan tekanan darah systolic dan diastolic pada pasien hipertensi. Selain itu, sejalan dengan Penelitian Taylor, Farquhar, Nelson, dan Agras (1997) pada penderita hipertensi esensial menunjukkan manfaat relaksasi yang dapat menurunkan tekanan darah sistolik dan diastolik sebesar 14/5 mmHg.

Faktor penting yang menunjang keberhasilan sebuah penelitian adalah modul terapi relaksasi zikir, fasilitator, dan karakteristik partisipan. Modul terapi relaksasi zikir ini merupakan modifikasi terapi yang sudah dilakukan pada penelitian sebelumnya. Terapi relaksasi zikir disusun sebagai bentuk intervensi bagi para pasien hipertensi esensial pralansia yang mengalami kecemasan. Metode yang ada pada terapi relaksasi zikir ini adalah pemberian informasi tentang kecemasan, psikoedukasi dengan pendekatan islami, penggalian masalah, 
pengungkapan ide dan perasaaan serta harapan dari setiap peserta dalam mengikuti proses terapi, saling berbagi pengalaman dan adanya problem solving dari masing-masing peserta dan terapis, melakukan proses relaksasi dan zikir bersama.

Setelah semua peserta mengetahui tentang kondisi yang mereka alami, kemudian pada tahap selanjutnya terapis memberikan informasi dan praktek mengenai relaksasi otot progresif terhadap keluhan fisik dari setiap peserta. Adanya informasi dan praktek relaksasi otot progresif ini membantu peserta mengenali dan mengurangi ketegangan yang terjadi karena kecemasan. Terapis juga menyediakan waktu bagi peserta untuk saling memberikan pengalaman yang dirasakan sebelum dan sesudah melakukan relaksasi otot progresif. Hal ini juga tidak terlepas dari dinamika yang terjadi pada kelompok eksperimen yang juga ikut berperan aktif dalam menjalankan proses terapi ini sehingga bisa menurunkan kecemasan yang dialami oleh pasien. Hal ini juga di dukung oleh penelitian relaksasi yang dilakukan oleh Patel dan North (1975) pada penderita hipertensi esensial dan hasilnya dapat menurunkan tekanan darah sistolik dan diastolic 26,1/15 mmHG.

Selain pemberian relaksasi otot progresif tersebut, tahap selanjutnya terapis memberikan penjelasan mengenai zikir dan mengajak semua peserta melakukan zikir bersama-sama. Dengan melakukan zikir setiap peserta merasa lebih tenang dan ketegangan mereka berkurang. Banyak faktor yang memengaruhi muncul- nya kondisi lapangdada pada seseorang. Nashori (2007), menyebutkan beberapa faktor yang memengaruhi kelapangdadaan seseorang, di antaranya adalah zikir. Ketika berzikir, seseorang mengingat besarnya kuasa Allah Swt dalam hidupnya sehingga manusia memasrahkan segala sesuatu hanya pada Allah Swt. Hal ini sesuai dengan tulisan dari Al-Hafidz ibn Al-Qayyim Al-Jauziyah (Saleh, 2010) bahwa manfaat zikir yang dirasakan manusia salah satunya adalah zikir akan membawa seseorang menyerahkan dirinya kepada Allah sehingga perlahan Allah menjadi tempat perlindungan dari segala hal.

\section{SIMPULAN DAN SARAN}

\section{Simpulan}

Berdasarkan hasil penelitian yang telah dilakukan, maka dapat disimpulkan bahwa terapi relaksasi zikir mempunyai pengaruh terhadap penurunan kecemasan pada pasien hipertensi esensial pralansia. Artinya, ada perbedaan tingkat kecemasan kelompok eksperimen setelah diberi terapi relaksasi zikir dan kelompok kontrol yang tidak diberi terapi relaksasi zikir. Kelompok eksperimen memiliki tingkat kecemasan lebih rendah dibandingkan dengan kelompok kontrol.

\section{Saran}

Berdasarkan kesimpulan penelitian dan keterbatasan yang terdapat pada penelitian ini, maka terdapat beberapa hal yang dapat disarankan dalam rangka mengembangkan relaksasi zikir. Pertama, saran untuk Puskesmas Godean 2. Bagi Pihak Puskesmas Godean 2 agar bisa 
lebih memfasilitasi kesehatan psikologis yang menyangkut kecemasan terhadap penyakit hipertensi esensial pralansia khususnya. Selain itu, bisa memberikan tambahan terapi secara spiritual sesuai dengan agama pasien yaitu agama islam. Program dari Puskemas untuk pembentukan Pagayuban berupa perkumpulan pasien yang menderita hipertensi esensial pralansia sehingga dapat diorganisir secara tepat dan lebih efektif.

Kedua: saran untuk aplikasi profesi psikologi. Terapi relaksasi zikir belum menjadi perhatian banyak pada profesi psikologi, sehingga modul berupa penerapan terapi psikologi islami yang bersifat relaksasi zikir tidak banyak ditemukan di bidang psikologi.

Ketiga: saran untuk institusi pendidikan. Pihak Magister Profesi Psikologi diharapkan dapat memasukkan kurikulum tentang terapi islami yaitu berupa terapi relaksasi zikir baik secara kelompok maupun secara individual sebagai pilihan intervensi psikologis.

Keempat: saran bagi peneliti berikutnya. Aspek kecemasan hipertensi esensial pralansia belum menjadi perhatian banyak bagi para peneliti, khususnya kecemasan pada orang yang sakit. Oleh karena itu, perlu dikembangkan instrument pengukuran variabel kecemasan pasien hipertensi esensial pralansia dengan bahasa yang lebih mudah dimengerti, sehingga dapat digunakan pada semua orang. Untuk peneliti selanjutnya, diperlukan seleksi sampel penelitian yang lebih banyak, serta variabel lain yang dapat memengaruhi penurunan kecemasan pada pasien hipertensi esensial pralansia.

\section{DAFTAR PUSTAKA}

Azwar, S. (2000). Penyusunan Skala Psikologi. Yogyakarta: Pustaka pelajar.

Calhoun, J. E., \& Acocella, J. J. (1990). Psychology of Adjustment and Human Relationship. New York: Mc. Graw Hill Publishing Company.

Goldfried M. R., Greenberg, L., \& Marmar, C. (1990). Individual Psychoterapy: Process and Outcome. Annual review of Psychology, 41, 659-688.

Greenberger, D., \& Padesky, C. A. 1995. Mind over Mood: Change How You Feel by Changing The Way You Think. New York: The Guildford Press.

Hoelscher, T.J. and Lichstein, K.L. (1986). Home Relaxation Practice in Hypertension Treatment: Objective Assesment and Complience Induction. Journal of Consulting and Clinical Psychology, 54, 2.

Kaplan, H.I \& Sadock, B. J. (1994). Sinopsis Psikiatri: Ilmu Pengetahuan Perilaku Psikiatri Klinis Edisi Ketujuh Jilid 2. Jakarta: Binarupa Aksara.

Maimunah, A. (2011). Pengaruh Pelatihan Relaksasi dengan Dzikir untuk Mengatasi Kecemasan Ibu Hamil Pertama. Tesis. Yogyakarta: Fakultas Psikologi Universitas Gadjah Mada. 
Nashori, H.F. (2007). Kelapangdadaan Survivor Bencana Gempa di Yogyakarta. Jurnal Religiusitas, 1 (3), 97-112.

Nevid, J. S; Rathus, S.A; \& Greene, B. (2005). Psikologi Abnormal Edisi Kelima Jilid 1. Jakarta: Erlangga.

Newberg, A.B. (2000). Spritual Practice and Health. Spirituality and Medicine Connection, Vol. 4, Issues 1, Spring.

Patel. C.H., and North, W.R. (1975). Randomized Controlled Trial of Yoga and Biofeedback in the Management of Hipertension. Lancet, ii, 93-95.

Rachmawati, I. (2007). Hubungan antara Religiusitas dengan Kecemasan Pasien Penderita Penyakit Kronis. http://www.jiptummpp.ac.id.

Saleh, A. Y. (2010). Berdzikir untuk Kesehatan Syaraf. Jakarta: Penerbit Zaman.
Santrock, J. W. (2002). Life-Span Development: Perkembangan Masa Hidup (terjemahan). Jakarta: Erlangga.

Shadish, W.R, Cook, T.D, Campbell, D.T. (2002). Experimental and Quasi Experimental Design For Generalized Causal Inference. NewYork: Houghton Mufflin Company.

Sustrani, L., Alam, S., \& Hadibroto, I. (2006). Hipertensi: Informasi Lengkap untuk Penderita dan Keluarganya. Jakarta: PT. Gramedia Pustaka Utama.

Taylor, C.B., Farquhar, J.W., Nelson, E., and Agras, W.S. (1997). The Effect of Relaxation Therapy Upon High Blood Pressure. Archive of General Psychiatry, 34, 339-342.

Wilianto, V. M. 2009. Terapi Musik Kognitif Perilaku untuk Menurunkan Kecemasan Pada Penderita Tekanan Darah Tinggi. Tesis. Yogyakarta: Fakultas Psikologi Universitas Gadjah Mada. 